\title{
Social Jetlag and Excessive Daytime Sleepiness from a Sample of Russian Children and Adolescents
}

\author{
Sergey N Kolomeichuk $\mathbb{D}^{1,2}$ \\ Christoph Randler $\mathbb{D}^{3}$ \\ Artem $\vee$ Morozov 4 \\ Denis G Gubin (iD ${ }^{2,5}$ \\ Christopher L Drake (iD ${ }^{6}$ \\ 'Laboratory of Genetics, Institute of \\ Biology, Karelian Science Centre, Russian \\ Academy of Sciences, Petrozavodsk, \\ Russia; ${ }^{2}$ Tyumen State Medical University, \\ Tyumen, Russia; ${ }^{3}$ University of Tuebingen, \\ Department of Biology, Tübingen, \\ D-72076, Germany; ${ }^{4}$ Laboratory of \\ Ecological Physiology of Animals, Institute \\ of Biology, Karelian Science Centre, \\ Russian Academy of Sciences, \\ Petrozavodsk, Russia; ${ }^{5}$ Tyumen \\ Cardiology Research Center, Tomsk \\ National Research Medical Center, \\ Russian Academy of Science, Tomsk, \\ Russia; ${ }^{6}$ Henry Ford Hospital Sleep \\ Disorders and Research Center, Detroit, \\ MI, USA
}

Purpose: Insufficient nocturnal sleep is a primary source of excessive daytime sleepiness. Most previous research has focused on the disparity between sleep demands and study start times in adolescents. Fewer studies have focused on elementary schoolchildren. We hypothesize that late sleep timing is connected to excessive daytime sleepiness in a sample of Russian children and adolescents. The major goals of our study were to evaluate excessive daytime sleepiness in Russian schoolchildren and adolescents using the Russian version of the Pediatric Daytime Sleepiness Scale (PDSS) and to estimate its relationship with sleepwake parameters using the Munich Chronotype Questionnaire (MCTQ).

Materials and Methods: Student subjects were from public educational facilities in the Republic of Karelia. They completed both the PDSS and the Munich Chronotype Questionnaire to estimate sleep parameters and chronotype (MSFsc). Five hundred and eleven students provided data for the PDSS and sleep-wake variables, and 479 for the full MCTQ data.

Results: The overall prevalence of Excessive Daytime Sleepiness (EDS) in our sample was $18 \%$. The total PDSS score was inversely correlated with sleep length on school nights and was independent of respondents' sex. Higher PDSS scores were associated with later bedtimes on school days and free days, and shorter sleep duration on school days. Late chronotype and more pronounced social jetlag were both positively correlated with high PDSS scores. A negative correlation was found between chronotype and the duration of the sleep period on weekdays $(p<0.001)$ and a positive correlation was found on weekends $(p<$ 0.001). Longer average sleep duration was positively related to less daytime sleepiness.

Conclusion: This study suggests that excessive daytime sleepiness is chronotypedependent. School start times could be shifted to a later hour to prolong sleep and reduce EDS.

Keywords: adolescents, children, sleepiness, pediatric daytime sleepiness scale, sleep duration, social jetlag

\section{Plain Language Summary}

Insufficient sleep at night is the major reason for excessive daytime sleepiness (EDS), thus children and adolescents feel sleepy during the day. In this study, we assessed the daytime sleepiness of children and adolescents in Russia and looked for associations with chronotype and social jetlag. We measured EDS using the Pediatric Daytime Sleepiness Scale (PDSS). Five hundred and eleven students from public schools in Northern Russia completed the PDSS and the Munich Chronotype Questionnaire (MCTQ). EDS was found in $18 \%$ of the children and adolescents. Daytime sleepiness was higher when sleep duration on school nights was shorter. Sleepiness was higher when children and adolescents went to bed later on school and vacant days. Evening students and students with a high social jetlag were sleepier
Correspondence: Christoph Randler University of Tuebingen, Department of Biology, Auf der Morgenstelle 24, Tübingen, D-72076, Germany

Tel +49-707I-20746II

Email christoph.randler@uni-tuebingen.de 
during the day. The results of this study suggest that excessive daytime sleepiness is chronotype-dependent.

\section{Introduction}

It is widely acknowledged that sleep is a crucial physiological process for replenishing daily energy expenditures and for consolidating memory. ${ }^{1}$ The recommended amount of sleep differs among age cohorts and reflects ontogenetic physiological changes. However, sleep loss is one of the most common health issues among children and adolescents worldwide. ${ }^{2}$ In many developed countries, it is common for students to experience sleep shortages on school days while restoring their sleep needs on free days-which is also known as oversleeping on the weekends. ${ }^{3,4}$ The discrepancy between sleep patterns during the week and weekend has been reported in residents of megalopolises, as well as those of smaller settlements in Northern Russia. ${ }^{5}$ Further, studies conducted in Russia, ${ }^{6}$ Germany, ${ }^{7,8}$ and Turkey ${ }^{9}$ have shown that this difference is more pronounced in the western part of a particular time zone.

Sleep loss or curtailment is a primary cause of excessive daytime sleepiness (EDS). ${ }^{10,11}$ EDS is believed to be a serious health issue affecting nearly half of the children and adolescents globally. ${ }^{12}$ The reported prevalence of EDS is dependent on the survey tool used, sample size of the cohort, geographical region, time that the survey was conducted, age, and other factors. Studies have variously reported EDS percentages ranging from $10 \%$ to $20 \%$ in prepubescent children, ${ }^{13,14}$ and from $16 \%$ to $47 \%$ in adolescents. ${ }^{15}$ Gradisar et al have pointed out that, in comparison with adolescents from North America and Europe, Asian adolescents commonly experience later bedtimes and shorter total sleep times, explaining the higher rate and severity of EDS in the analyzed population. ${ }^{16}$ To better estimate daytime sleepiness in children, Drake et al $^{17}$ developed a measurement tool tailored for pediatric sleepiness, the Pediatric Daytime Sleepiness Scale (PDSS). They found that daytime sleepiness was associated with academic failure, attention deficiencies, and other unfavorable life outcomes. ${ }^{18}$ The PDSS is a self-assessment tool that quantifies sleeping habits and problems in different situations, ${ }^{19}$ as well as the attention of adolescents. ${ }^{20}$ Numerous studies have proved that the PDSS is applicable for children 11-15 years old. ${ }^{17,18,21,22}$ Researchers frequently use the PDSS in various studies, including application in healthy persons and children with various pathologies. ${ }^{17,18,23-25}$ In teenagers, evaluations of EDS prevalence have been reported from $15 \%$ in Korea to $53 \%$ in Turkey when the PDSS was applied. ${ }^{21,26}$
To address the lack of available tools for estimating pediatric EDS in our research, we translated and validated the Russian version of the PDSS. ${ }^{27}$ Numerous studies of note focus on the discrepancy between school start times in adolescents and university students; ${ }^{28}$ fewer studies concentrate on preschoolers and young schoolchildren. ${ }^{29}$ However, it is of interest to know how the transition to puberty affects daytime sleepiness and sleep parameters in children living in Russia. In this case, age was used as a surrogate for puberty. Among the few, Komada et $\mathrm{al}^{30}$ revealed that social jetlag and daytime sleepiness were associated in a sample of Japanese schoolchildren 11-16 years old. According to their study, social jetlag paired with short sleep duration on school days is one of the main factors linked to daytime sleepiness.

The present work was performed using the Russian version of the PDSS to assess excessive daytime sleepiness and to find the relationships between sleep variables, chronotype, and social jetlag in the Northern European part of Russia. No previous work has assessed sleep parameters and daytime sleepiness in Russian junior scholars aged 10 or younger. We hypothesize that late timing is connected to excessive daytime sleepiness. Additionally, we used older children to illustrate the chronotype shift toward evening orientation.

\section{Materials and Methods}

The research was conducted in Petrozavodsk $\left(61^{\circ} 47^{\prime} \mathrm{N}\right.$ $\left.34^{\circ} 20^{\prime} \mathrm{E}\right)$ and Kem' (64 $\left.{ }^{\circ} 57^{\prime} \mathrm{N} 34^{\circ} 34 \mathrm{E}\right)$ during April and May 2018. During this time period, day length is between 13:30 and 19:00 hours. Subjects were recruited for the study from selected schools in municipalities situated in Northern Russia that took part in the cooperative study. Subjects included Russian schoolchildren and adolescents aged 7 to 17 years old. The total study sample consisted of 511 students aged 7-17 years (mean [SD] age: 10.39 [2.36] years, $49 \%$ boys). Information on key variables was missing for 33 subjects $(6.5 \%)$, who were excluded from the analysis. The school start time was 8:30 a.m. in all assessed institutions.

The inclusion criteria for participation in the study were acceptable reading and writing skills in Russian, as well as the age. All participants and their parents were informed about the aims of the study prior to enrollment, and written informed consent was obtained from the parent or legal guardian before being administered the survey. A validated Russian version of the PDSS, ${ }^{27}$ and the Munich Chronotype Questionnaire (MCTQ), ${ }^{31}$ were distributed to the participants in paper form. Monthly family 
income evaluation was done according to Russian Household Income Report. ${ }^{32}$ We found the family income in the low to middle range (1-low income [N=197], 2median income [ $\mathrm{N}=261]$ and 3- high income [ $\mathrm{N}=9]$, no answer: $\mathrm{N}=44$ ). Students voluntarily completed the surveys during school activities. To protect personal information, the completed questionnaires were obtained by the researchers. Neither the teachers nor classmates viewed the answers of any study participant.

This study was approved by the Joint Ethics Committee from Petrozavodsk State University and Karelian Ministry of Health and Social Development (Protocol \# 41 from 06.09.2018) in accordance with ethical principles described in the Declaration of Helsinki.

\section{The Pediatric Daytime Sleepiness Scale (PDSS)}

The Pediatric Daytime Sleepiness Scale (PDSS) is an 8 -item questionnaire that assesses EDS in school children and adolescents; the questionnaire was translated into Russian. $^{27}$ These authors established the reliability and validity of the scale by exploratory and confirmatory factor analyses and Cronbach's alpha, as well as by test-retest reliability. The 5-point Likert scale ranges from 0 (never) to 4 (always). Item 3 is reverse coded. Rankings on all the items were calculated to get the total score from 0 to 32 . Higher scores represented greater daytime sleepiness.

\section{Social Jetlag and Habitual Bed and Rise Times}

To obtain information on chronotype and additional sleep measures, each respondent also filled in the MCTQ. We have successfully used a validated Russian version of the MCTQ in several prior studies of Russian children and adolescents. ${ }^{5,33}$ Participant responses to the MCTQ were used to calculate self-reported sleep parameters on both school days and free days, including social jetlag, sleep duration, and the midpoint of sleep, which is an operationalization of chronotype. Chronotypes are given by mid-sleep on free days corrected (MSFc), which represents a phase of the sleep-wake cycle. MSFsc is the corrected midpoint of sleep, accounting for weekend oversleep, i.e, it differs from the simple midpoint of sleep on free days. For details of calculation, see Roenneberg et al. ${ }^{8}$ MCTQ parameters are expressed in hours, ranging from 0 hour (extreme and morningness) to 12 hours (extreme eveningness). We processed completed surveys as previously described. ${ }^{31}$ The response rate towards the clock times is lower compared to the Likerttype questionnaires [own, unpublished observations] which led to lower samples in the MCTQ responses compared to the PDSS.

Positive social jetlag values reflected a later mid-sleep on free days than on school days. ${ }^{6,31}$ To determine the source of EDS for the Russian schoolchildren, we analyzed possible links between sleep parameters and PDSS values.

\section{Statistical Analyses}

Statistical analyses were conducted using SPSS 26.0 (IBM, Armonk, NY, USA). Sleep parameters reported by the subject elementary school children, middle school, and high school adolescents were compared by using analysis of variance (ANOVA) followed by post hoc tests. The links between the PDSS score and sleep variables were investigated by using bivariate correlation analysis. To assess the influence of sleep parameters on daytime sleepiness simultaneously, we used a linear regression.

\section{Results}

Descriptive statistics for PDSS scores and sleep characteristics are shown in Table 1. The reliability of the Russian version of the PDSS was confirmed by analyzing Cronbach's alpha for the data set. After inversion of item 3 , the internal consistency of the PDSS scale was found to

Table I Descriptive Statistics of the Sample

\begin{tabular}{|l|c|c|}
\hline & Mean & SD \\
\hline PDSS score & 11.58 & 5.94 \\
\hline Wake up time school day & $7: 11$ & $0: 41$ \\
\hline Wake up time free days & $9: 28$ & $1: 39$ \\
\hline Bed time school day & $22: 43$ & $1: 07$ \\
\hline Bed time free day & $23: 29$ & $1: 27$ \\
\hline Sleep duration school days & $8: 28$ & $1: 18$ \\
\hline Sleep duration free days & $9: 58$ & $1: 48$ \\
\hline Average sleep duration & $9: 33$ & $1: 27$ \\
\hline Midpoint of Sleep school days & $2: 57$ & $0: 40$ \\
\hline Midpoint of Sleep free days & $4: 28$ & $1: 16$ \\
\hline MSFsc & $4: 15$ & $1: 10$ \\
\hline Social jetlag & 91 & 69 \\
\hline
\end{tabular}

Note: Variables are presented as the mean [SD]. Bedtime. wake-up time. sleep duration and mid-sleep times are presented in hours: minutes. Social jetlag is shown in minutes. 
Table 2 Factor Loadings of the Single Items Onto the PDSS

\begin{tabular}{|l|c|}
\hline & Factor Loadings \\
\hline Item I & 0.72 I \\
\hline Item 2 & 0.638 \\
\hline Item 3 & -0.386 \\
\hline Item 4 & 0.587 \\
\hline Item 5 & 0.546 \\
\hline Item 6 & 0.676 \\
\hline Item 7 & 0.568 \\
\hline Item 8 & 0.729 \\
\hline
\end{tabular}

Note: Please note that item 3 is reverse coded and was reversed to calculate the PDSS sum score.

be acceptable, with Cronbach's alpha of 0.757. An exploratory principal component factor analysis indicated a one-factor solution, with an eigenvalue of 3.0 (37.89\% of variance explained; Table 2). The second factor had an eigenvalue of 0.9 . This finding corroborates previous work on the dimensionality of this scale performed in different countries. ${ }^{17,18,30}$ The distribution of PDSS scores among study participants is shown in Figure 1.
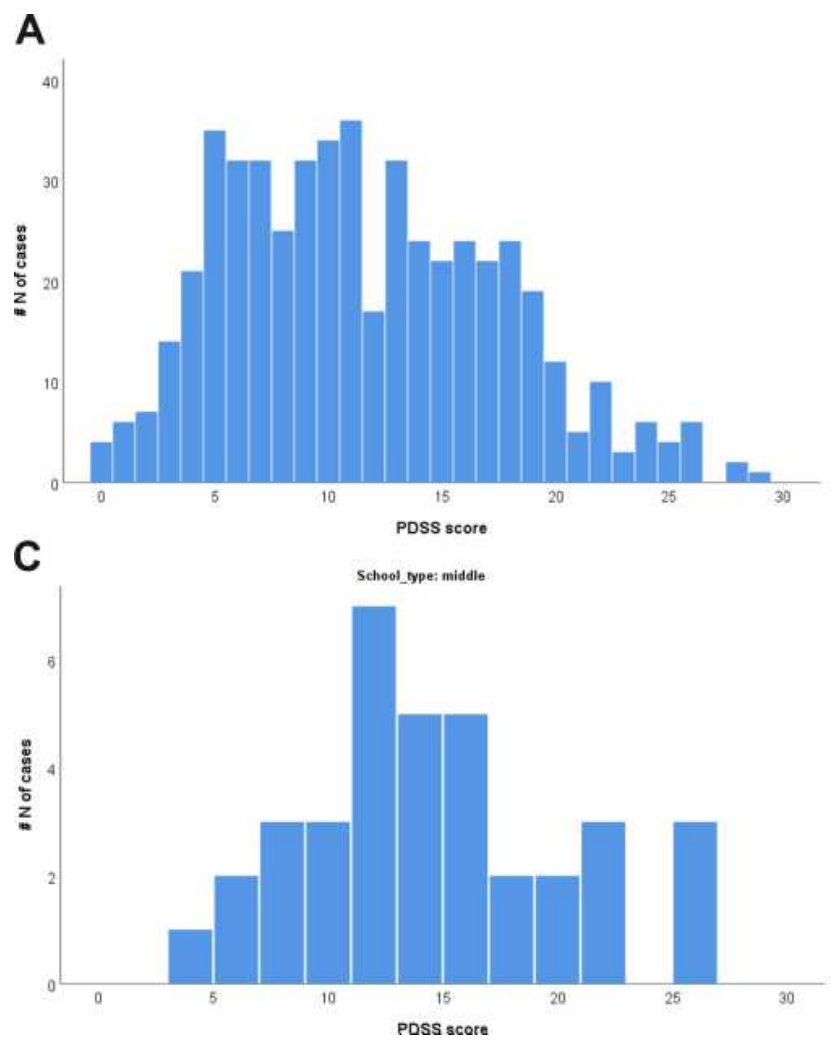

The mean PDSS score for all participants was 11.58 [5.94] (Figure 1). The mean score was 11.10 [5.90] for elementary school students in 1st to 4th grades, 14.11 [5.75] for middle school children in 5th to 8th grades, and 13.76 [5.61] for high school students in 9th to 11th grades (Figure 1A-D). Table 3 shows the data for the sleep variables recorded in the study sample. There were significant differences found by ANOVA among the three groups (elementary, middle, and high school), except in the wake time on school days. In the present study of Russian children and adolescents, mean bedtimes and sleep durations on school days were 22:27 and 8 hours 43 minutes for elementary school students (7-11 years old); $23: 25$ and 7 hours 43 minutes for middle school students (12-14 years old); and 23:32 and 7 hours 03 minutes for high school students (15-17 years old), respectively see Table 3 .

We detected an overall rate of EDS in Russian school children of $18 \%$, which had a PDSS score $>17$, which translated to excessive daytime sleepiness (criteria published by Yang et al) ${ }^{22}$ The prevalence of EDS in the group of elementary school-aged children was $16.7 \%$. By comparison, it was $25 \%$ in middle school-aged children and $23.5 \%$ in high school students.

B

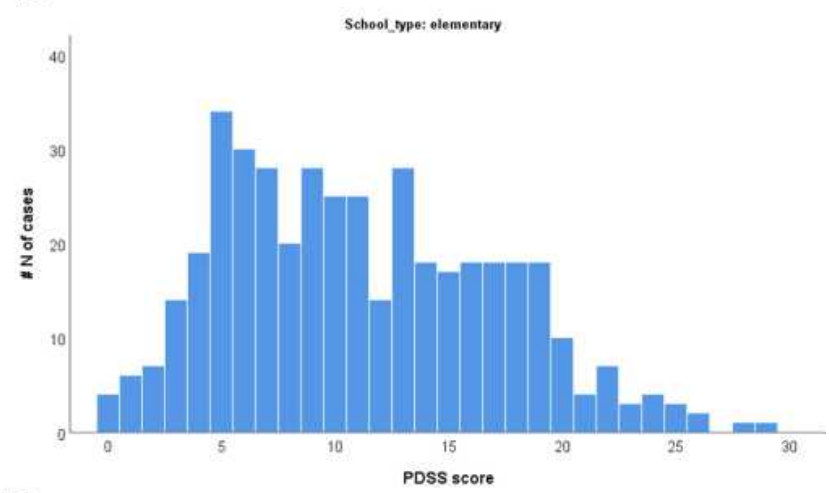

D

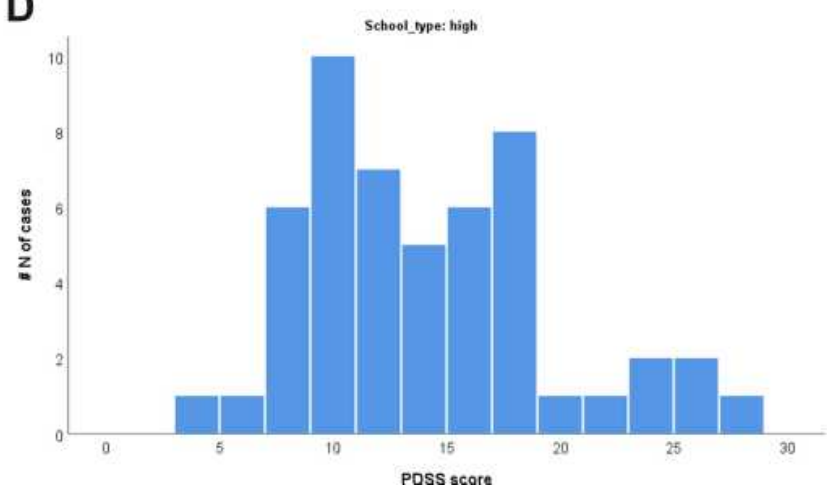

Figure I Frequency distribution of PDSS-RUS scores in full sample (A), elementary school (B), middle school (C), and high school (D). 
Table 3 Sleep Variables of Schoolchildren in Various Grades

\begin{tabular}{|c|c|c|c|c|}
\hline & Elementary School (E) & Middle School (M) & High School (H) & \\
\hline & $N=393$ & $N=36$ & $\mathbf{N}=\mathbf{5 0}$ & \\
\hline & Mean (SD) & Mean (SD) & Mean (SD) & Post Hoc p value \\
\hline Wake-up time school day & $7: 13(0: 43)$ & $7: 05(0: 28)$ & 7:04 (0:30) & 0.236 \\
\hline Wake -up time free days & $9: 22(1: 36)$ & $9: 57(1: 43))$ & $9: 52(1: 45)$ & $0.022 ; \mathrm{E}<\mathrm{M}=\mathrm{H}$ \\
\hline Bed time school day & $22: 30(0: 58)$ & $23: 25(1: 15)$ & $0: 01 \quad(1: 03)$ & $<0.00 \mathrm{I} ; \mathrm{E}<\mathrm{M}<\mathrm{H}$ \\
\hline Bed time free day & $23: 13(1: 16)$ & $0: 28(I: 53)$ & $0: 53(1: 23)$ & $<0.00 \mathrm{I} ; \mathrm{E}<\mathrm{M}<\mathrm{H}$ \\
\hline Sleep duration school days & $8: 43(1: 10)$ & $7: 40(1: 24)$ & 7:03 (1:07) & $<0.00 \mathrm{I} ; \mathrm{E}>\mathrm{M}>\mathrm{H}$ \\
\hline Sleep duration free days & $10: 09(1: 49)$ & $9: 29(1: 26)$ & $8: 58(1: 25)$ & $<0.00 \mathrm{I} ; \mathrm{E}>\mathrm{M}>\mathrm{H}$ \\
\hline Average sleep duration & $9: 44(1: 28)$ & $8: 58(1: 14)$ & $8: 26(1: 03)$ & $<0.001 ; E>M=H$ \\
\hline Midpoint of Sleep on school days & $2: 5 I(0: 37)$ & $3: 15(0: 39)$ & $3: 32(0: 36)$ & $<0.00 \mathrm{I} ; \mathrm{E}<\mathrm{M}<\mathrm{H}$ \\
\hline Midpoint of Sleep on free days & $4: 18(1: 08)$ & $5: 12(1: 39)$ & $5: 22(1: 25)$ & $<0.001 ; E<M=H$ \\
\hline Social jetlag & $\mathrm{I}: 26(\mathrm{I}: 07)$ & $\mathrm{I}: 57(\mathrm{I}: 23)$ & $\mathrm{I}: 49(\mathrm{I}: 06)$ & $0.004 ; E<M=H$ \\
\hline Chronotype(MSFsc) & $4: 05(1: 02)$ & 4:57 (I:34) & $5: 06(1: 16)$ & $<0.001 ; E<M=H$ \\
\hline
\end{tabular}

Notes: Variables are presented as the mean [SD]. Bedtime wake-up time sleep duration and mid-sleep times are presented in hours: minutes. Social jetlag is shown in minutes. Data were compared using analysis of variance (ANOVA) and post hoc analysis among grades (Ist-4th of elementary school. 5th-8th of middle school and 9-I I th of high school).

PDSS scores were weakly correlated with age (Table 4). Concerning sleep variables, higher PDSS scores were associated with later wake times on free days, later bedtimes on both free and school days, longer sleep duration on free days, and all measures of sleep mid-point, chronotype and social jetlag (Figure 2). Overall, school children with greater daytime sleepiness had more pronounced social jetlag and a later chronotype. Although these children experienced curtailed sleep on weekdays, they had longer sleep duration on the weekends, which can be interpreted as catch-up sleep.

We found substantial influences of social jetlag, average sleep duration and chronotype on PDSS scores (Table 5). Later chronotypes and higher social jetlag predicted a higher daytime sleepiness, while a longer average sleep duration predicted lower scores on the PDSS. In the regression analysis, the influence of age and gender was not-significant (Table 5). Concerning the standardized beta coefficients (Table 5), we found chronotype being the most influential statistical predictor of PDSS scores, followed by social jetlag and average sleep duration.

\section{Discussion}

This study analyzed daytime sleepiness in younger schoolchildren using the Russian version of the PDSS and assessed the relationships between PDSS scores and sleep parameters. This is the first work that documents daytime sleepiness and sleep parameters in elementary school children. Under the results of the original study, ${ }^{17}$ the PDSS proved to have adequate internal consistency, with an acceptable Cronbach's alpha coefficient among the study population. Exploratory factor analysis showed that the PDSS had a single-factor structure similar to that of the original version. We confirmed the previous finding that the Russian version of the PDSS valid in 7-12 years old schoolchildren $^{27}$ and expanded our study sample to include adolescents aged 12 to 17 . This corroborates data obtained previously in the United States, Argentina, Turkey, and Japan. ${ }^{17,18,26,30}$

The mean score and distribution of the PDSS were smaller than those published in the original version ${ }^{17}$ but were in line with results reported by Randler, ${ }^{34}$ Maganti, ${ }^{24}$ and $\mathrm{Rhie}^{21}$ for younger study cohorts. The discrepancy between our data and those in the original study can be attributed to the different age ranges of the study participants; data collected from older students in this study (i.e., middle and high school students) were in good agreement with those published previously. ${ }^{17,18,26,30}$

This region belongs to the high latitudes' area that may affect sleep parameters in children. We previously did the 
Table 4 Correlations Between PDSS Scores and Sleep-Wake Variables

\begin{tabular}{|c|c|c|}
\hline & & PDSS Score \\
\hline \multirow[t]{2}{*}{ Age } & $r$ & $0.098^{*}$ \\
\hline & $P$ & 0.027 \\
\hline \multirow[t]{2}{*}{ Wake up time school day } & $r$ & $0.101 *$ \\
\hline & $P$ & 0.026 \\
\hline \multirow[t]{2}{*}{ Wake up time free days } & $r$ & $0.240 * *$ \\
\hline & $P$ & $<0.001$ \\
\hline \multirow[t]{2}{*}{ Bedtime school days } & $r$ & $0.222 * *$ \\
\hline & $P$ & $<0.001$ \\
\hline \multirow[t]{2}{*}{ Bedtime freedays } & $r$ & $0.154 * *$ \\
\hline & $P$ & 0.001 \\
\hline \multirow[t]{2}{*}{ Sleep duration school days } & $r$ & $-.138 * *$ \\
\hline & $P$ & 0.002 \\
\hline \multirow[t]{2}{*}{ Sleep duration free days } & $r$ & $0.095^{*}$ \\
\hline & $P$ & 0.039 \\
\hline \multirow[t]{2}{*}{ Average sleep duration } & $r$ & 0.047 \\
\hline & $P$ & 0.304 \\
\hline \multirow[t]{2}{*}{ Midsleep time school days } & $r$ & $0.239 * *$ \\
\hline & $P$ & $<0.001$ \\
\hline \multirow[t]{2}{*}{ Midsleep time free days } & $r$ & $0.244 * *$ \\
\hline & $P$ & $<0.001$ \\
\hline \multirow[t]{2}{*}{ Social jetlag } & $r$ & $0.130 * *$ \\
\hline & $\mathrm{P}$ & 0.004 \\
\hline \multirow[t]{2}{*}{ Chronotype $\left(\mathrm{MSF}_{\mathrm{sc}}\right)$} & $r$ & $0.222 * *$ \\
\hline & $P$ & $<0.001$ \\
\hline
\end{tabular}

Notes: **Indicates $\mathrm{P}<0.01$, *Indicates $\mathrm{P}<0.05$.

pilot study to find seasonal changes in PDSS across European part of Russian North. ${ }^{35}$ Preliminary findings indicated higher PDSS values during autumn-winter time when compared to spring. We did not analyze sleep parameters in that work, ${ }^{35}$ so we plan to perform the original study simultaneously in low and high latitudes. This would give an insight into the relationship between latitude and day length on the one side and daytime sleepiness. Alternatively, it would also be an interesting part to do a meta-analysis on latitude and daytime sleepiness.
These findings conclude that elementary school children experience less daytime sleepiness, which poses a higher risk of sleepiness in adolescents, and may again support studies that request later school start times for adolescents, ${ }^{36,37}$ because later school start times lead to a longer sleep duration, which in turn should decrease daytime sleepiness. In this study, self-reported bedtimes on school days were similar to those of children in Asia, but the average duration of sleep was longer and more comparable to those of North American and European children. $^{16}$

As a novel aspect, we simultaneously tested different predictors of PDSS scores and found average sleep duration, social jetlag and chronotype as significant predictors of daytime sleepiness. We identified social jetlag as one key factor associated with daytime sleepiness after adjusting for age and sex. Furthermore, we found an influence of MSFsc on PDSS scores, strongly indicating that individuals with a late chronotype experience more daytime sleepiness. In combination with the results above, this finding supports recommendations for a later school start time for adolescents. ${ }^{28}$ Both the physiological and psychosocial changes that occur in puberty increase sleep needs in this group. Sleep is marked by a lag in the timing of sleep during puberty because of the variety of social, biological and psychological shifts typical of this period of human development. ${ }^{38}$ This delayed sleep onset can impair the transition to social hours, making it difficult for adolescents to remain awake in situations where they are expected to perform at their best, such as in school and during sports activities. Support for this idea comes from Agathao et al, ${ }^{39}$ who recently documented a significant increase in common mental disorders score among Brazilian schoolchildren with short sleep hours. Therefore, further examination of these conditions is warranted, because everyday activities, school and extracurricular schedules, and a lack of frequent physical activity, as well as abnormal anthropometric parameters such as body mass index (BMI), and nocturnal waking and respiratory disorders, are predictors of pathologies consistent with daytime sleepiness. We recommend not only that school schedules be shifted to accommodate the sleep needs of children, but also that the duration of school-night sleep be increased for some students to prevent daytime sleepiness. We also suggest that students adhere to programs taught in school. $^{38}$ 

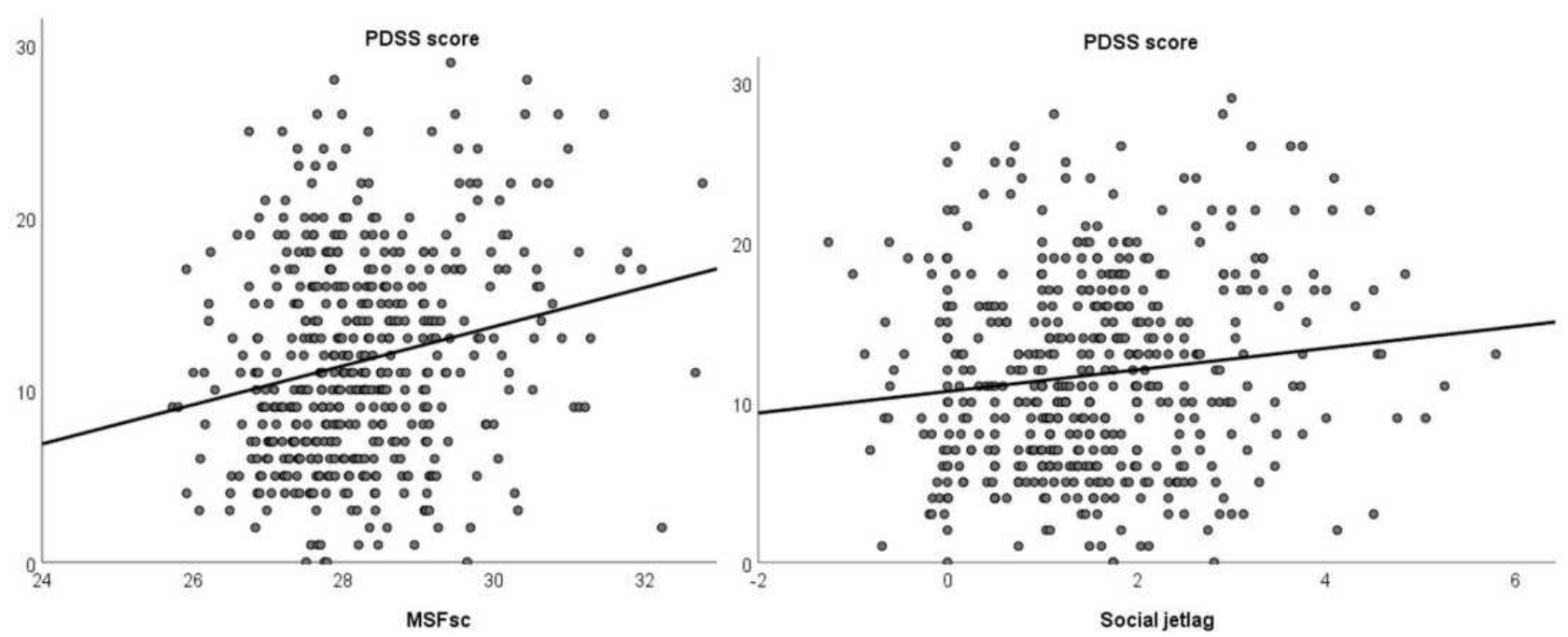

Figure 2 Relationship between daytime sleepiness (PDSS score) and chronotype (MSFsc) and Social Jetlag.

According to the original version of the PDSS, a score $>20$ indicates a clinical level of EDS. ${ }^{17}$ However, Yang et $\mathrm{al}^{22}$ reported that pathologies associated with excessive sleepiness were detectable at a lower threshold (PDSS $>17$ ). In this study, we used this lower threshold to better capture possible sleep disturbances that could be obscured by a higher threshold value; that is, PDSS $>20$. We suggest that a lower threshold may be more beneficial for screening purposes, whereas the higher threshold should be used for clinical practice.

Cultural differences could also affect sleep habits and related issues. ${ }^{16,35,38}$ For example, van Litsenburg $^{14}$ reported that Dutch scholars experienced more sleep disturbances compared with their counterparts in the United States and China. ${ }^{14}$ Dutch children also reported more problems with specific sleep parameters compared to those in the United States and China. Another study by Liu et $\mathrm{al}^{40}$ found a similar prevalence of sleep issues between Asian schoolchildren and their European peers but stressed significant differences related to childrens' sleep habits (bed sharing).

One of our limitations included the time zone we used for the study. The study was conducted in only one time zone, during spring, to eliminate confusions linked to school schedules, as well as day length. The second limitation was the lack of objective sleep assessment tools, like multiple sleep latency tests and actigraphy. Our future research in this area will also benefit from the inclusion of objective sleep assessment tools, such as multiple sleep latency tests and actigraphy. The third limitation was the restricted sample of children in our study, which was not based on a representative sample of the population. Additional studies are now needed to determine the prevalence of EDS across different time zones throughout Russia.

Table 5 Factors Affecting Daytime Sleepiness in Russian School Children, with PDSS Score as Dependent Variable and Age, Sex, Social Jetlag, Average Sleep Duration and Midpoint of Sleep as Independent Variables

\begin{tabular}{|l|l|l|l|l|l|}
\hline & Non Standardized Coefficient & SE & Standardized Beta & T & P \\
\hline Constant & -62.952 & 13.305 & & -4.732 & $<0.001$ \\
\hline Age & 0.133 & 0.124 & 0.053 & 1.072 & 0.284 \\
\hline Sex & 0.063 & 0.532 & 0.005 & 0.118 & 0.906 \\
\hline MSFsc & 2.437 & 0.459 & 0.477 & 5.309 & $<0.001$ \\
\hline Social jetlag & -1.607 & 0.467 & -0.309 & -3.442 & $\mathbf{0 . 0 0 1}$ \\
\hline Average sleep duration & 0.705 & 0.214 & 0.175 & 3.295 & $\mathbf{0 . 0 0 1}$ \\
\hline
\end{tabular}

Note: Numbers in bold show significant $p$ values. 
Also, we did not assess pubertal status relying on parents' reports or self-report. So, additional studies including pediatricians to estimate children's pubertal status are needed. Repeating the study in the winter months should be interesting because photoperiod/day length differs to a great extent in high latitudes, which might influence daytime sleepiness. One hypothesis would be a higher daytime sleepiness during winter.

\section{Conclusion}

As a conclusion, we could show that daytime sleepiness is related to later bedtimes and to late chronotype. For this reason, we suggest to delay school start times, which should result in longer night sleep duration, and hence, in less daytime sleepiness.

\section{Acknowledgments}

We are grateful to Petrozavodsk Private School (School Principal - Svetlana Kolomeichuk), Petrozavodsk School\#42 (Olga V. Malysheva), Kem' municipal educational district (Sergey V. Pausch; school principals, Elena Kuropteva and Tatyana Latysheva), Kem' sport school (Alexander Mironov) and Rabocheostrovsk rural school (school principal, Albina Smirnova). The study was carried out under state order (project № 0218-2019-0077) and (№ 0218-2019-0073) and by Government of Tyumen disctrict decret of 20.11.2020 No. 928-rp.

\section{Disclosure}

The authors report no conflicts of interest in this work.

\section{References}

1. Diekelmann S, Born J. The memory function of sleep. Nat Rev Neurosci. 2010;11(2):114-126. doi:10.1038/nrn2762

2. Fallone G, Seifer R, Acebo C, Carskadon MA. How well do school-aged children comply with imposed sleep schedules at home? Sleep. 2002;25:739-745. doi:10.1093/sleep/25.7.739

3. Crowley SJ, Acebo C, Carskadon MA. Sleep, circadian rhythms, and delayed phase in adolescence. Sleep Med. 2007;8(6):602-612. doi:10.1016/j.sleep.2006.12.002

4. Hasler BP, Dahl RE, Holm SM, et al. Weekend-weekday advances in sleep timing are associated with altered reward-related brain function in healthy adolescents. Biol Psychol. 2012;91(3):334-341. doi:10.1016/j.biopsycho.2012.08.008

5. Borisenkov MF, Perminova EV, Kosova AL. Chronotype, sleep length, and school achievement of 11-to 23-year-old students in northern European Russia. Chronobiol Int. 2010;27(6):1259-1270. doi:10.3109/07420528.2010.487624

6. Borisenkov MF, Kosova AL, Kasyanova ON. Impact of perinatal photoperiod on the chronotype of 11 to 18-year-olds in northern European Russia. Chronobiol Int. 2012;29(3):305-310. doi:10.3109/ 07420528.2011 .653612

7. Randler C. Morningness-eveningness comparison in adolescents from different countries around the world. Chronobiol Int. 2008;25 (6):1017-1028. doi:10.1080/07420520802551519
8. Roenneberg T, Kuehnle T, Juda M, et al. Epidemiology of the human circadian clock. Sleep Med Rev. 2007;11(6):429-438. doi:10.1016/j. smrv.2007.07.005

9. Masal E, Randler C, Beşoluk Ş, Önder İ, Horzum MB, Vollmer C. Effects of longitude, latitude and social factors on chronotype in Turkish students. Pers Individ Dif. 2015;86:73-81. doi:10.1016/j. paid.2015.05.019

10. Wolfson AR, Carskadon MA. Understanding adolescents' sleep patterns and school performance: a critical appraisal. Sleep Med Rev. 2003;7:491-506. doi:10.1016/S1087-0792(03)90003-7

11. Hershner SD, Chervin RD. Causes and consequences of sleepiness among college students. Nat Sci Sleep. 2014;6:73-84. doi:10.2147/ NSS.S62907

12. Gibson ES, Powles AP, Thabane L, et al. "Sleepiness" is serious in adolescence: two surveys of 3235 Canadian students. BMC Public Health. 2006;6(1):116. doi:10.1186/1471-2458-6-116

13. Calhoun SL, Vgontzas AN, Fernandez-Mendoza J, et al. Prevalence and risk factors of excessive daytime sleepiness in a community sample of young children: the role of obesity, asthma, anxiety/ depression,and sleep. Sleep. 2011;34(4):503-507. doi:10.1093/sleep/ 34.4 .503

14. van Litsenburg RRL, Waumans RC, van den Berg G, Gemke RJ. Sleep habits and sleep disturbances in Dutch children: a population-based study. Eur J Pediatr. 2010;169(8):1009-1015. doi:10.1007/s00431-010-1169-8

15. Liu X, Liu L, Owens JA, Kaplan DL. Sleep patterns and sleep problems among schoolchildren in the United States and China. Pediatrics. 2005;115:241-249. doi:10.1542/peds.2004-0815F

16. Gradisar M, Gardner G, Dohnt H. Recent worldwide sleep patterns and problems during adolescence: a review and meta-analysis of age, region, and sleep. Sleep Med. 2011;12(2):110-118. doi:10.1016/j. sleep.2010.11.008

17. Drake C, Nickel C, Burduvali E, Roth T, Jefferson C, Pietro B. The pediatric daytime sleepiness scale (PDSS): sleep habits and school outcomes in middle-school children. Sleep. 2003;26:455-458. doi:10.1037/t02761-000

18. Perez-Chada D, Perez-Lloret S, Videla AJ, et al. Sleep-disordered breathing and daytime sleepiness are associated with poor academic performance in teenagers. A study using the pediatric daytime sleepiness scale (PDSS). Sleep. 2007;30:1698-1703. doi:10.1093/sleep/ 30.12.1698

19. Pereira ÉF, Teixeira CS, Louzada FM. Daytime sleepiness in adolescents: prevalence and associated factors. Revista Paulista De Pediatria. 2010;28(1):98-103. doi:10.1590/S010305822010000100015

20. Perez-Lloret S, Videla AJ, Richaudeau A, et al. A multi-step pathway connecting short sleep duration to daytime somnolence, reduced attention, and poor academic performance: an exploratory cross-sectional study in teenagers. J Clin Sleep Med. 2013;9 (5):469-473. doi:10.5664/jcsm.2668

21. Rhie S, Lee S, Chae KY. Sleep patterns and school performance of Korean adolescents assessed using a Korean version of the pediatric daytime sleepiness scale. Korean J Pediatr. 2011;54(1):29. doi:10.3345/kjp.2011.54.1.29

22. Yang CM, Huang YS, Song YC. Clinical utility of the Chinese version of the pediatric daytime sleepiness scale in children with obstructive sleep apnea syndrome and narcolepsy. Psychiatry Clin Neurosci. 2010;64(2):134-140. doi:10.1111/j.1440-1819.2009.02054.x

23. Huamaní C, Rey de Castro J. Somnolencia y características del sueño en escolares de un distrito urbano de Lima, Perú. Archivos argentinos de pediatría. 2014;112(3):239-241. doi:10.5546/ aap.2014.239

24. Maganti R, Hausman N, Koehn M, Sandok E, Glurich I, Mukesh BN. Excessive daytime sleepiness and sleep complaints among children with epilepsy. Epilepsy Behav. 2006;8:272-277. doi:10.1016/j. yebeh.2005.11.002 
25. Ferrari Junior GJ, Drake CL, Barbosa DG, Andrade RD, Silva DAS, Felden EP. Factor structure of the Brazilian version of Pediatric Daytime Sleepiness Scale. Chronobiol Int. 2018;35(8):1088-1094. doi:10.1080/07420528.2018.1458732

26. Bektas M, Bektas I, Ayar D, et al. Psychometric properties of Turkish version of pediatric daytime sleepiness scale (PDSS-T). Asian Nurs Res. 2016;10(1):62-67. doi:10.1016/j.anr.2016.01.002

27. Randler C, Kolomeichuk SN, Morozov AV, et al. Psychometric properties of the Russian version of the Pediatric Daytime Sleepiness Scale (PDSS). Heliyon. 2019;5(7):e02134. doi:10.1016/j. heliyon.2019.e02134

28. Minges KE, Redeker NS. Delayed school start times and adolescent sleep: a systematic review of the experimental evidence. Sleep Med Rev. 2016;28:86-95. doi:10.1016/j.smrv.2015.06.002

29. Arbabi T, Vollmer C, Dörfler T, Randler C. The influence of chronotype and intelligence on academic achievement in primary school is mediated by conscientiousness, midpoint of sleep and motivation. Chronobiol Int. 2015;32(3):349-357. doi:10.3109/ 07420528.2014.980508

30. Komada Y, Breugelmans R, Drake CL, et al. Social jetlag affects subjective daytime sleepiness in school-aged children and adolescents: a study using the Japanese version of the Pediatric Daytime Sleepiness Scale (PDSS-J). Chronobiol Int. 2016;33(10):1311-1319. doi:10.1080/07420528.2016.1213739

31. Wittmann M, Dinich J, Merrow M, Roenneberg T. Social jetlag: misalignment of biological and social time. Chronobiol Int. 2006;23 (1-2):497-509. doi:10.1080/07420520500545979

32. Federal State Statistics Service. Population Census. Available from. https://eng.rosstat.gov.ru/folder/76215 Accessed May 20, 2021.
33. Kolomeichuk SN, Randler C, Shabalina IM, Fradkova LI, Borisenkov MF. Chronotype of children and adolescents influences their academic achievements - evidence from Russian Karelia. Biol Rhythm Res. 2016;47(6):873-883. doi:10.1080/ 09291016.2016.1207352

34. Schneider AM, Randler C. Daytime sleepiness during transition into daylight saving time in adolescents: are owls higher at risk? Sleep Med. 2009;10(9):1047-1050. doi:10.1016/j.sleep.2008.08.009

35. Kolomeichuk SN, Morozov AV, Petrashova DA, et al. Daytime sleepiness and sleep parameters in children living in the European north of Russia. Yakut Med Jl. 2019. doi:10.25789/ymj.2019.67.26

36. Owens JA, Belon K, Moss P. Impact of delaying school start time on adolescent sleep, mood, and behavior. Arch Pediatr Adolesc Med. 2010;164:608-614. doi:10.1001/archpediatrics.2010.96

37. Wheaton AG, Chapman DP, Croft J. School start times, sleep, behavioral, health, and academic outcomes: a review of the literature. $J$ Sch Health. 2016;86(5):363-381. doi:10.1111/josh.12388

38. Randler C, Vollmer C, Kalb N, Itzek-Greulich H. Breakpoints of time in bed, midpoint of sleep, and social jetlag from infancy to early adulthood. Sleep Med. 2019;57:80-86. doi:10.1016/j. sleep.2019.01.023

39. Agathao BT, Lopez PS, Cunha DB, Sichieri R. Gender differences in the impact of sleep duration on common mental disorders in school students. BMC Public Health. 2020;20(1):148. doi:10.1186/s12889020-8260-5

40. Liu X, Liu L, Wang R. Bed sharing, sleep habits, and sleep problems among Chinese school-aged children. Sleep. 2003;26:839-844. doi:10.1093/sleep/26.7.839

\section{Publish your work in this journal}

Nature and Science of Sleep is an international, peer-reviewed, open access journal covering all aspects of sleep science and sleep medicine, including the neurophysiology and functions of sleep, the genetics of sleep, sleep and society, biological rhythms, dreaming, sleep disorders and therapy, and strategies to optimize healthy sleep.
The manuscript management system is completely online and includes a very quick and fair peer-review system, which is all easy to use. Visit http://www.dovepress.com/testimonials.php to read real quotes from published authors. 